\title{
Advancements in stem cell-derived hepatocyte-like cell models for hepatotoxicity testing
}

\author{
Meixian Jin ${ }^{1}$, Xiao Yi ${ }^{2}$, Wei Liao ${ }^{3}$, Qi Chen ${ }^{1}$, Wanren Yang ${ }^{3}$, Yang $\mathrm{Li}^{3}$, Shao $\mathrm{Li}^{3}$, Yi Gao ${ }^{3}$, Qing Peng ${ }^{3 *}$ and \\ Shuqin Zhou ${ }^{1 *}$ (D)
}

\begin{abstract}
Drug-induced liver injury (DILI) is one of the leading causes of clinical trial failures and high drug attrition rates. Currently, the commonly used hepatocyte models include primary human hepatocytes (PHHs), animal models, and hepatic cell lines. However, these models have disadvantages that include species-specific differences or inconvenient cell extraction methods. Therefore, a novel, inexpensive, efficient, and accurate model that can be applied to drug screening is urgently needed. Owing to their self-renewable ability, source abundance, and multipotent competence, stem cells are stable sources of drug hepatotoxicity screening models. Because 3D culture can mimic the in vivo microenvironment more accurately than can 2D culture, the former is commonly used for hepatocyte culture and drug screening. In this review, we introduce the different sources of stem cells used to generate hepatocyte-like cells and the models for hepatotoxicity testing that use stem cell-derived hepatocyte-like cells.
\end{abstract}

Keywords: Stem cells, Hepatocyte-like cells, Drug screening, Drug-induced liver injury, 3D cell culture

\section{Introduction}

Drug-induced liver injury (DILI) is one of the main reasons for the withdrawal of new drugs from the market and is also an important factor leading to the failure of drug development. In Western countries, the annual incidence of DILI is 1 to 20 cases per 100,000 inhabitants [1-3]. In China, a retrospective study found an estimated incidence of 23.8 DILI cases per 100,000 persons per year, which is higher than that reported for Western countries [4]. The safety of drugs has always been a

\footnotetext{
*Correspondence: zhujiangzhuanhua@163.com; zhoushuqin@smu.edu.cn ${ }^{3}$ General Surgery Center, Department of Hepatobiliary Surgery II, Guangdong Provincial Research Center for Artificial Organ and Tissue Engineering, Guangzhou Clinical Research and Transformation Center for Artificial Liver, Institute of Regenerative Medicine, Zhujiang Hospital, Southern Medical University, Guangzhou, Guangdong Province, China

'Department of Anesthesiology, Zhujiang Hospital, Southern Medical University, Guangzhou 510000, China

Full list of author information is available at the end of the article
}

focus, and finding a reasonable and efficient drug prediction model is a great challenge in the pharmaceutical field [5].

DILI can be divided into intrinsic or idiosyncratic DILI (iDILI). Intrinsic DILI is typically dose-related and predictable. It transpires within a short period and shows insignificant individual differences. iDILI is less commonly seen in clinical practice; it is unpredictable and features significant individual differences related to age, sex, genetic factors, the environment, and associated basic diseases. Thus, the assessment of iDILI is one of the most challenging liver diseases for hepatologists because of its relatively low incidence, distinct individual differences, diverse manifestations, and lack of typical biomarkers [6-8].

Various hepatocyte models have been developed for drug safety tests (Table 1). 


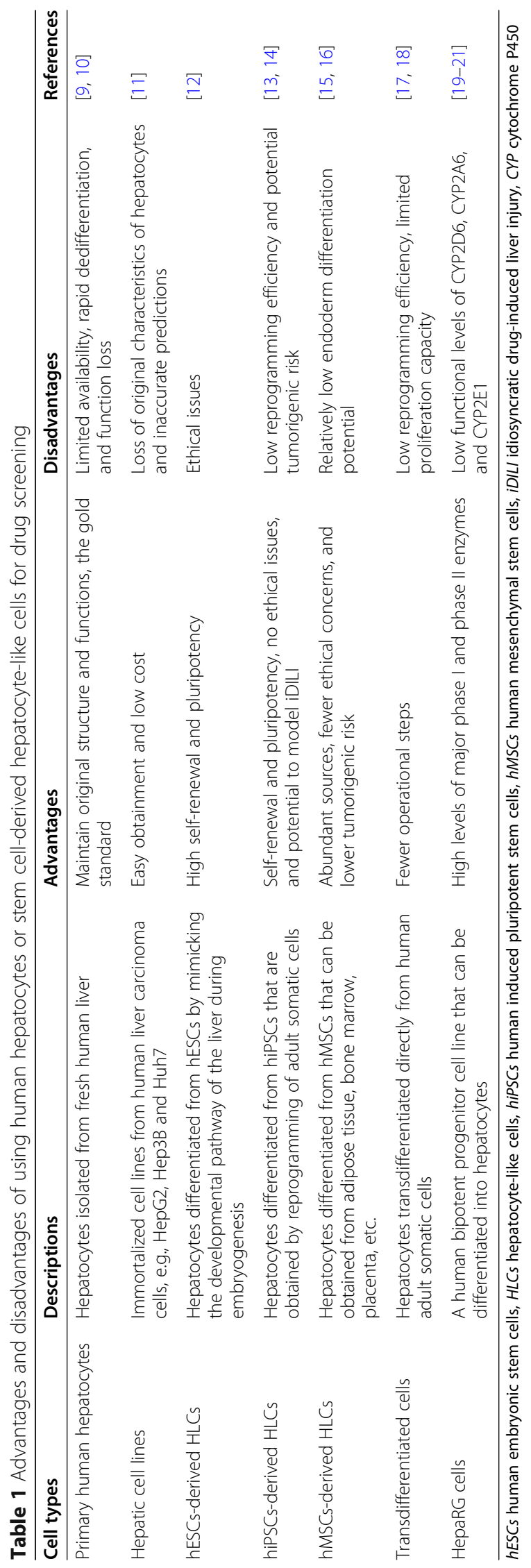


With considerable interspecies differences in drug metabolism, animal models cannot accurately reflect the metabolic response of drugs in humans, and high costs and ethical issues also limit the application of animal models [22]. Isolated primary human hepatocytes (PHHs) maintain their original structure and most of their function in vivo, so they are an ideal model for evaluating drug metabolism and toxicity and thus are "gold standard" models for drug testing [9]. However, their rapid phenotype change and short life span seriously affect the accuracy of predicting drug metabolism [10, 23]. Hepatic cell lines are inexpensive and can reproduce indefinitely, but they lose the original characteristics of hepatocytes in long-term culture in vitro and cannot effectively reflect the complex metabolic effects of drugs in vivo [11].

Recently, stem cells have been widely used in regenerative medicine, safety pharmacology, toxicology research, regenerative medicine, and cell therapy. Because of their source abundance, self-renewable ability, high proliferative potential, and multipotent competences, stem cells are stable sources of hepatocytes for safe pharmacology and toxicology evaluation. In this sense, stem cell-derived hepatocytes are able to overcome the shortcomings of traditional hepatocyte models, such as interspecies differences and insufficient cellular function. Three-dimensional (3D) culture technology has enabled the formation of cell-cell and cell-matrix interactions and can better maintain cell activity and function; hence, with $3 \mathrm{D}$ culture, liver tissue engineering has undergone a paradigm shift from classic monolayer cell culture to more advanced organotypic liver models [24]. With the rapid development of stem cell technology, scientists are paying more attention to stem cells, hoping to establish a more effective evaluation model of hepatotoxicity in vitro by using stem cells [25]. In addition, the use of stem cells allows for assessing drug toxicity in vivo. Also, humanized mouse models based on stem cell-derived hepatocytes provide good information about drug metabolism, disposition, and toxicity in humans and can contribute to the development of personalized medicine strategies, which would improve drug efficacy and safety [26]. Studies of "hepatocytes" derived from stem cells have focused on generating a closer representation of the mature $\mathrm{PHH}$ phenotype, and the term hepatocyte-like cells (HLCs) is commonly used to describe these cells [27].

In this review, we focus on the technology of stem cell differentiation into HLCs and the current uses of stem cells for hepatotoxicity evaluation.

\section{Generation of hepatocyte-like cells from stem cells}

hESCs, hiPSCs, and hMSCs

Thomson et al. [12] found that the human embryonic stem cells (hESCs) expressed high levels of telomerase activity, so these cells still maintained the developmental potential to form trophoblast and derivatives of all three embryonic germ layers even after undifferentiated proliferation in vitro for a long time. Although hESCs have high self-renewing potency and pluripotency, their use is limited owing to the ethical issues involved in the process of separation. Induced pluripotent stem cells are reprogrammed from adult somatic cells by introducing four factors: Oct3/4, Sox2, c-Myc, and Klf4. These cells exhibit a gene expression pattern, epigenetic profile, and differentiation potential similar to hESCs [28]. Because they are easy to obtain without evoking ethical problems and have unique advantages in the study of iDILI, the use of human induced pluripotent stem cells (hiPSCs) differentiated into hepatocytes has gradually become a research hotspot [13, 14]. Human mesenchymal stem cells (hMSCs) can be isolated from various somatic tissues, such as adipose tissue, bone marrow, placenta, umbilical cord, and menstrual blood [15, 29-32]. As compared with hESCs/hiPSCs, the use of hMSCs leads to fewer ethical concerns, and the tumorigenesis risk is also lower, but the expansion capacity and ability to differentiate into endoderm are relatively lower [16].

Most of the current protocols attempt to promote the differentiation of stem cells by mimicking the development of the liver during embryogenesis in three steps: definitive endoderm differentiation, hepatocyte differentiation, and hepatocyte maturation. Hepatic growth factor, fibroblast growth factor, activin A, oncostatin $\mathrm{M}$, and other cytokines play important roles in different differentiation stages [33-36]. In the current methods, HLCs exhibit an immature hepatic phenotype (e.g., express fetal markers such as alpha fetoprotein) [37, 38]. In particular, the gene expression and enzyme activity of cytochromes P450 (CYPs) are far less than those of PHHs in hiPSC-derived HLCs [39, 40]. Another study showed that as compared with PHHs, many genes in HLCs involved in xenobiotic metabolism remain low, and gene regulatory network analysis showed that HLCs contain features of not only liver but also stem cells, intestine, and fibroblasts [41]. Therefore, the induction protocol needs to be further optimized before using HLCs as an alternative to hepatocytes in drug research.

Researchers have shown that the use of small molecules $[42,43]$ regulating the extracellular nutrient level $[44,45]$, inducing overexpression of hepatic transcription factors [46, 47], and manipulating miRNA expression $[48,49]$ represents powerful methods for the efficient generation of metabolically functional hepatocytes. However, substantial variation in differentiation efficiencies has been observed among different stem cell lines, and a set of consensus criteria is needed to assess whether HLCs are suitable for drug testing. In this regard, some experts suggest that drug screening systems should be 
evaluated in terms of the viability, morphology, functionality, and toxicity features [50].

\section{Transdifferentiation}

Researchers have tried to skip over iPSC differentiation and directly convert terminally differentiated cells into hepatocytes [51]. Huang et al. demonstrated that overexpression of transcription factors such as FOXA3, HNF1A, and HNF4A directly induced fibroblasts into human-induced hepatocytes (hiHeps). Although hiHeps express hepatic gene programs and display functions characteristic of hepatocytes, there is still a large gap in cell metabolic rate between hiHeps and primary hepatocytes [17]. In addition, Fu et al. [18] described a protocol for achieving the efficient conversion of human primary hepatocytes into liver progenitor-like cells by the delivery of developmentally relevant cues, including NAD+-dependent deacetylase SIRT1 signaling. These progenitor-like cells can redifferentiate to achieve mature hepatic functions. However, the cells feature individual variation: most cannot be cultured beyond 20 passages, and they show reduced proliferation capacity, reduced expression of progenitor markers, and chromosomal abnormalities in the late passage.

\section{HepaRG cells}

The HepaRG cell line is a human bipotent progenitor cell line that can be differentiated into HLCs and biliary epithelial cells [19]. Whole-genome expression profiling showed that HepaRG cells are remarkably similar to human hepatocyte populations [52]. In fact, HepaRG cells maintain liver cell functions, drug-metabolizing enzymes, hepatobiliary transporters, and nuclear receptors better than do other hepatic cell lines [53]. A multiparametric screening assay showed that oxidative stress, mitochondrial damage, and disorders of neutral lipid metabolism were changed notably in HepaRG cells exposed to DILIrelated drugs, which accounts for their high sensitivity as compared with other cell lines [54]. A high concentration of DMSO required in standard differentiation protocols limits the use of HepaRG cells $[55,56]$, but studies have shown that 3D culture or a cocktail of soluble molecules can be used as an alternative to the DMSO-based differentiation protocol for HepaRG $[57,58]$. In addition, even though HepaRG cells express high functional levels of most phase I and II enzymes, the levels of some metabolic enzymes such as cytochromes P450 2A6 (CYP2A6), CYP2D6, and CYP2E1 still remain low [20, 21].

\section{Hepatocyte-like cell models for hepatotoxicity testing \\ 2D models}

2D monolayer cell culture is a traditional in vitro model for studying the response of cells to drugs that has the advantages of easy and low-cost operation. A few studies have applied stem cell-derived hepatocytes for drug toxicity testing, demonstrating their sensitivity and predictive power in identifying drugs with hepatoxic effects. Although the hepatocyte-like cell model is not as good as that of primary hepatocytes in some respects, the accuracy of drug prediction is far higher than that of hepatic cell lines [59, 60]. An analysis of 12 compounds showed an R2 correlation coefficient of 0.94 for TC50 values obtained for stem cell-derived hepatocytes and primary hepatocytes, which was higher than the R2 coefficient of 0.62 obtained for HepG2 cells. Also, HLCs demonstrated all toxicological endpoints typically examined, including steatosis, apoptosis, and cholestasis [61]. In addition to the direct toxic effects of drugs on liver cells, immune reaction is also involved in the pathogenesis of DILI. Proinflammatory and anti-inflammatory cytokine levels are increased when hESC-derived HLCs are treated with acetaminophen or thiazolidinedione. Kim et al. [62] demonstrated the potential of hESCderived HLCs in an in vitro model system for assessing drug-induced hepatotoxic immunological events (Table 2).

Furthermore, the HLC model allows for highthroughput drug screening and long-term drug toxicity assessment. Ware et al. [63] used a set of 47 drugs to assess the sensitivity and specificity of iPSC-derived HLCs for DILI predictions based on a micropatterned coculture system. For 37 of these hepatotoxic drugs, the sensitivity of the HLCs and PHHs was $65 \%$ and $70 \%$, respectively, with a specificity of $100 \%$ for the 10 nonhepatotoxic drugs. Thus, HLCs were quite sensitive and specific to the detection of drug toxicity as compared with PHHs. Long-term culture of HLCs is needed for evaluating chronic hepatoxicity. Holmgren et al. [64] demonstrated that HLCs showed a time-dependent toxic response to amiodarone, aflatoxin $\mathrm{B} 1$, and troglitazone when exposed to hepatotoxic compounds for 14 days. Unfortunately, the study lacked data on primary hepatocytes and compared HLCs with only HepG2 cells.

\section{D organoid models}

Cells are exposed to a dynamic environment in vivo. The oxygen gradient, nutrient concentration, fluid shear stress, and fluid friction force may significantly affect the hepatic differentiation of stem cells $[65,66]$. The static monolayer $2 \mathrm{D}$ culture model does not reproduce these conditions, so it cannot maintain the complete drug metabolic capacity of the cells, which may result in non-predictive or misleading data for in vivo drug responses. However, a 3D culture is able to mimic in vivo nutrient and oxygen concentration gradient as well as cell-cell and cell-matrix 


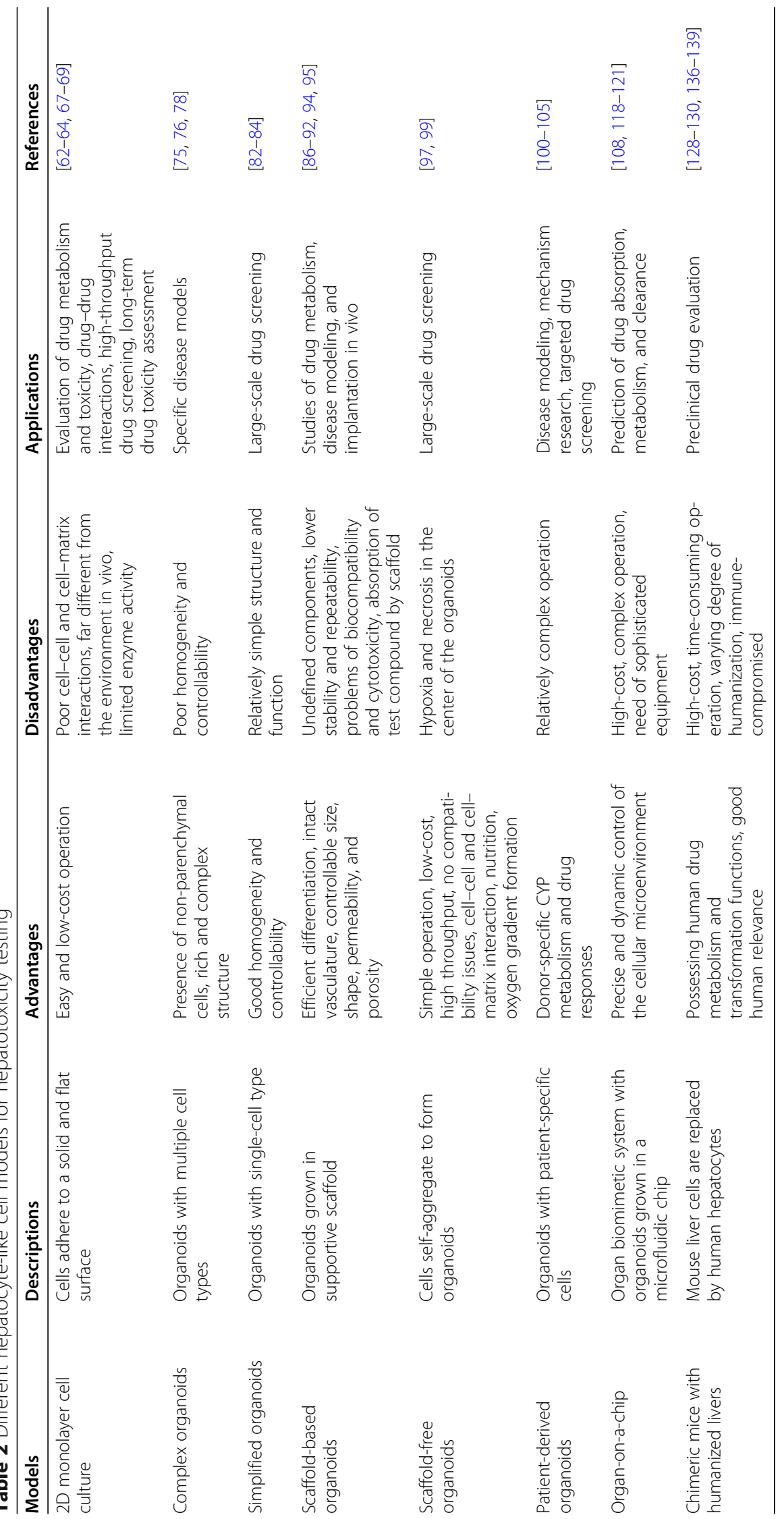


interactions, has greater stability, and promotes a longer lifespan than does 2D cell culture. Whether stem cells are differentiated or used for predicting drug toxicity, a 3D system is better than a $2 \mathrm{D}$ system [6769]. In recent years, 3D culture technology has developed rapidly and is now used for the development of organoids, spheroids, scaffolds, bioreactors, microfluidic devices, and 3D bioprinting. Organoid technology is one of the most promising 3D models for various applications in regenerative medicine, disease modeling, drug discovery, and hepatotoxicity [70] (Table 2).

Organoids create structures that resemble their organ of origin by assembling themselves into a 3D structure while growing and expanding in vitro. Because organoid models can reproduce organ-specific characteristics, including cellular architecture, morphology, and function, organoid technology has emerged as a powerful and revolutionary strategy enabling studies of disease and has applications for drug discovery and clinical treatments (Fig. 1). However, in the last decade, the meaning of "organoid" has come to encompass a range of cell culture techniques, not necessarily a single technique [71]. Here, we define an organoid as an in vitro 3D cellular cluster derived exclusively from primary tissue, pluripotent stem cells or progenitor cells that is capable of self-renewal and self-organization and exhibits similar organ functionality as the tissue of origin [72-74].

\section{Complex and simplified organoids}

The liver is mainly composed of hepatocytes, a type of parenchymal cell, but non-parenchymal cells, such as endothelial cells of the hepatic sinus, Kupffer cells, stellate cells, and lymphocytes, also play important roles. Non-parenchymal cells can enhance the maturation of hepatocytes by regulating some key pathways $[75,76]$. The ability of human endothelial cells (hECs) to secrete endogenous angiogenic factors might facilitate the recruitment of new blood vessels to the transplantation site [77]; thus, multicellular co-culture is widely used in organoid culture (Fig. 1). HLCs derived from hiPSCs were co-cultured with stromal cell populations, human umbilical vein endothelial cells, and hMSCs on Matrigel matrix to form a vascularized and functional liver tissue mass termed a liver bud. Immunostaining and gene expression analyses revealed a resemblance between in vitro-grown iPSC-derived liver buds and in vivo liver buds [78]. Recently, a variety of different organoid culture methods have been described, and hESCs, hiPSCs, hMSCs, and other stem cells have been reported to form organoids [79-81].

Multicellular co-cultured organoids have abundant structural levels, mimicking the complex niche components and interactions in vivo to a greater extent. However, for drug screening, some experts consider that the organoids should have high prediction power by recapitulating critical aspects of the target in vivo, and

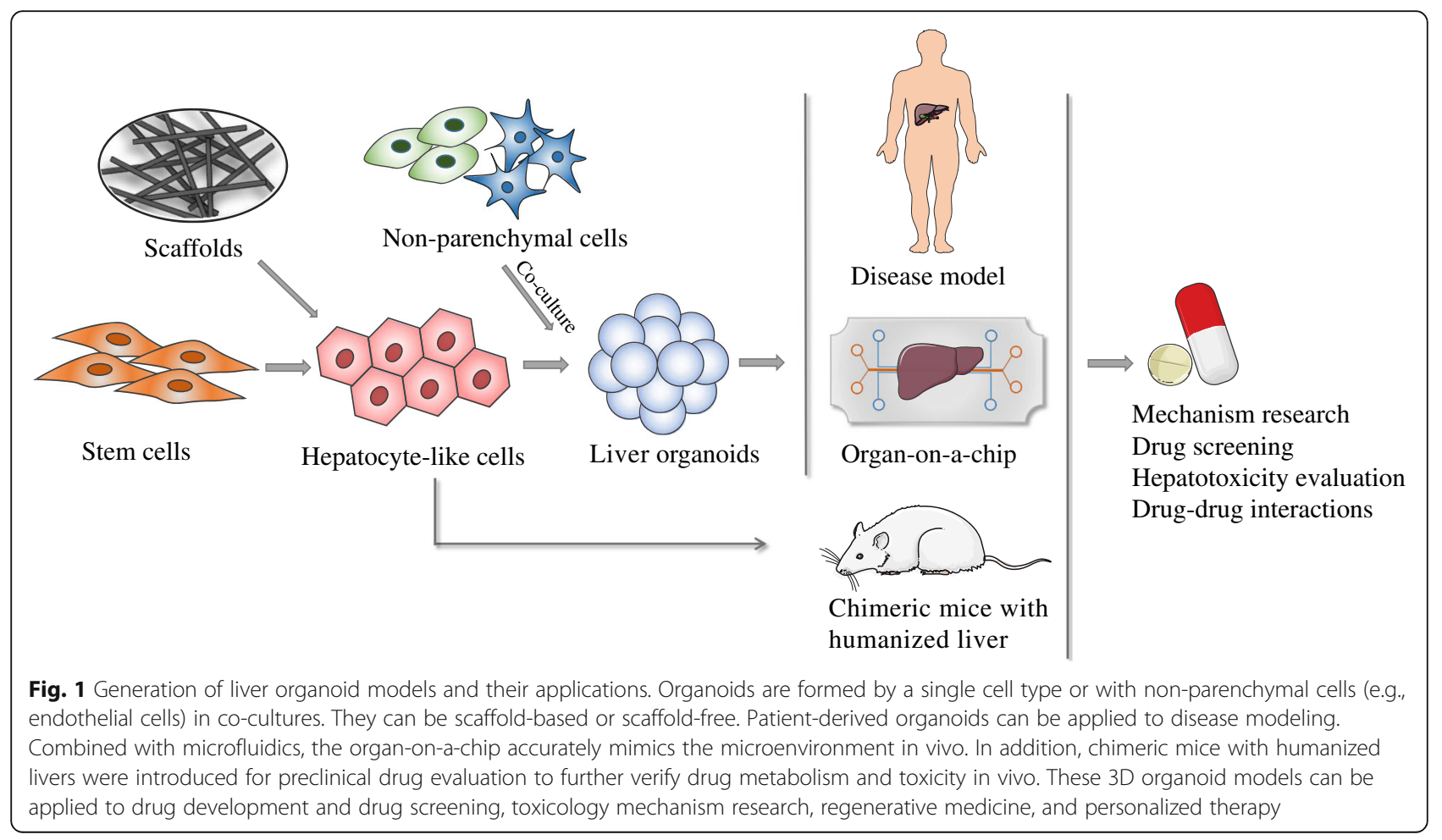


simplified procedures are necessary to maintain the homogeneity of the system. Wu et al. [82] established a system to generate hiPSC-derived functional hepatobiliary organoids in vitro without using exogenous cells or DNA transfection. Specifically, this kind of organoid displayed not only hepatocyte function but also the ability to efflux rhodamine and store bile acid. Moreover, after transplantation into immune-deficient mice, the organoids survived for more than 8 weeks. Mun et al. [83] reported that their organoids preserved mature liver properties, including serum protein production, drug metabolism and detoxification functions, active mitochondrial bioenergetics, and regenerative and inflammatory responses. When used for drug screening, the organoids exhibited significant toxic responses to clinically relevant concentrations of drugs that had been withdrawn from the market due to hepatotoxicity. One of the major challenges with the use of hepatic cells in drug screening assays is their loss of detoxification capacity during prolonged cultivation. However, Rashidi et al. [84] reported that their organoids, formed with hiPSCs, exhibited stable CYP3A activity for more than 1 year in culture, thus providing an attractive resource for longterm drug testing in vitro. Moreover, the levels of CYP3A4 and CYP1A2 in the organoids were much higher than those in 2D cultures, and the highest sensitivity to acetaminophen was detected in the organoids even at low concentrations [85].

Thus, for specific disease models, multiplexed organoids accurately mimic the in vivo environment, but simplified organoids with good homogeneity and controllability are more applicable in large-scale drug screening. Both simple and complex culture systems have their pros and cons. How to achieve a balance among efficiency, simplicity, complexity, and controllability needs more exploration.

\section{Scaffold-based and scaffold-free organoids}

Scaffolds for cell culture are mainly divided into biological and artificial scaffolds. Biocompatibility is better with biological than artificial scaffolds, and the former can better mimic the environment in vivo. Synthetic scaffolds can be used to artificially regulate some characteristics, such as size, shape, hardness, permeability, and porosity, and have better reproducibility and stability than biological scaffolds $[86,87]$. Biological scaffolds that are commonly used include natural polymers such as Matrigel, collagen, chitosan, gelatin, cellulose, and alginate. In general, organoid derivation protocols rely mainly on the use of Matrigel. Although Matrigel improves cell growth and efficient differentiation, its complex, illdefined, and variable components and batch-to-batch variability have led to an uncontrolled cellular microenvironment and reduced repeatability [88]. The use of a natural extracellular matrix (ECM) with better biocompatibility or artificial scaffolds with controlled mechanical characteristics can further define the self-organization of organoids and their functional level. Hydrogels with high biocompatibility and tunable properties, such as permeability, elasticity, stiffness, and chemical reactivity, can mimic the native ECM microenvironment by maintaining spatiotemporal control over biochemical and physical cues [89]. Several defined hydrogels have been shown to facilitate organoid formation as substitutes for Matrigel to improve the reproducibility and maturity of organoids by precisely controlling their componential, structure, and mechanical conditions [90, 91]. In addition, decellularized liver scaffolds provide a biomimetic natural organ scaffold with highly intact native ECM, vascular networks, and mechanical strength. Repopulated cells in these decellularized whole-liver scaffolds are organized in a natural manner and perform a high level of biomimetic liver functions better than do conventional 2D culture systems [92]. Decellularized liver matrix is an ideal scaffold, but because of the complicated process, high cost, and concerns about the relevant differences between human and animal liver architecture and immunological reactions, the application of a decellularized liver matrix has some limitations [93].

For artificial scaffolds, we have more choices. The synthetic polymers are the basis of 3D scaffold culture, among which poly-lactic acid, poly-glycolic acid, and poly-caprolactone are the commonly used materials (Fig. 1). Especially, nanofibrous scaffolds formed by electrospinning are expected to be an ideal tool for tissue engineering because they are biocompatible scaffolds with topographic structures that can be fabricated to mimic the structures of natural ECM. Many studies showed that nanofibrous scaffolds are a good choice in regenerative medicine [94]. In addition, 3D bio-printing technology allows for the use of different materials to produce scaffolds with defined shapes and geometries. The generation of HLCs showed improved morphological organization, increased liver-specific gene expression, increased metabolic product secretion, and enhanced CYP induction in a 3D printed model. The application of bioprinting technology in tissue engineering allows for the development of a 3D biomimetic liver model that recapitulates the native liver module architecture and could be used for various applications such as early drug screening and disease modeling $[95,96]$.

However, the current methods for culturing organoids are usually costly and time-consuming. Scaffold-free approaches may overcome the problems. Some of the commonly used techniques are the hanging drop method, rotational culture or agitation, and use of low-adhesion plates to promote self-aggregation [97, 98]. To enable mass production of viable cell cultures, a bioreactor and a microwell array platform have been used for culturing 
organoids [81, 99]. As compared with the scaffold-based method, the scaffold-free model is simple and low-cost and implies no need to consider histocompatibility. Therefore, it is more suitable for large-scale drug screening.

\section{Patient-derived organoids}

The drug metabolic capacity of hepatocytes varies greatly among individuals. iDILI is often caused by poor metabolism or genetic disorders. iDILI is related to a variety of factors, so with animal tests and traditional models, predicting the hepatotoxicity of some drugs is difficult. One cannot conduct in vitro studies on PHHs from patients with iDILI; however, patient-derived organoids can be important tools for iDILI because iPSCinduced HLCs retain donor-specific CYP metabolism and drug responses [100]. Human organoids have been used to investigate infectious diseases, immune diseases, genetic diseases, and cancer. The use of organoids has led to the establishment of an in vitro personalized hepatic model system for disease modeling, drug discovery, and drug toxicity studies. For example, organoids from A1AT-deficient patients can be expanded in vitro and mimic in vivo pathology [101]. Ouchi et al. [102] successfully developed an organoid model of steatohepatitis. Using 11 different healthy and diseased pluripotent stem cell lines, the authors developed a reproducible method to derive multicellular human liver organoids composed of hepatocyte-, stellate-, and Kupffer-like cells that exhibited transcriptomic resemblance to the in vivo-derived tissues. Under free fatty acid treatment, these organoids successively recapitulated key features of steatohepatitis, including steatosis, inflammation, and fibrosis phenotypes. More importantly, organoids from patients with genetic dysfunction of lysosomal acid lipase phenocopied severe steatohepatitis and were successfully treated by suppression of farnesoid $\mathrm{X}$ receptor agonism-mediated reactive oxygen species. Furthermore, other disease models have been successfully established, such as rheumatoid arthritis [103], citrullinemia [104], and alcoholic liver injury models [105]. Thus, the patient-derived organoid platform is an effective tool for studying the mechanisms of disease and screening targeted drugs for human genetic disorders and allow for further progress in personalized treatment development.

\section{Organ-on-a-chip}

Organs-on-chips are microfluidic devices for culturing living cells in continuously perfused, micrometer-sized chambers that model the physiological functions of tissues and organs. The microfluidic system supplies a continuous flow of fresh medium and facilitates constant removal of metabolic waste, thus providing a consistent microenvironment to maintain cell viability and function over a long culture period. By manipulating the cell culture microenvironment with high precision, the efficiency of reprogramming human somatic cells into hiPSCs can be greatly improved [106, 107]. Wang et al. [108] established a liver organoid-on-a-chip system by using microengineering techniques, and the liver organoids exhibited dose- and time-dependent hepatotoxic responses after exposure to acetaminophen. Some experts believe that the microfluidic organoids for drug screening platforms may be cost-effective tools for the "fail early, fail cheaply" paradigm of drug development [109].

In vivo, organs and tissues do not exist in isolation but rather reside in a highly integrated and dynamically interactive environment in which they interact and support each other [110]. In addition to the liver-on-a-chip, a series of organs-on-chips, including the lungs [111], kidneys [112], intestines [113], and blood vessels [114], have been developed by use of microfluidic technology. Several laboratories have established multiorgan chips, such as liver-kidney coculture biochips and four-organ chips of the intestine, liver, skin, and kidney, which have shown a great advantage in evaluating pharmacokinetic and pharmacodynamic parameters [115-117]. For example, Schimek et al. [118] designed an integrated lungliver organ chip. The authors found that aflatoxin B1, which has hepatotoxicity and carcinogenesis, impaired the function of lung tissues but had a protective effect when liver organoids were present. In contrast, in a multi-organ-on-a-chip system consisting of liver and cancer models, the anticancer prodrug capecitabine inhibited the proliferation of cancer cells after being metabolized by HepaRG cells [119]. Therefore, more complex drug metabolic reactions can be observed when several types of organoids are integrated into a single platform. The function of one organoid may influence the response of downstream organs, which is similar to how drugs are metabolized in vivo in that a drug may be metabolized by several organs [120]. Integrated multiorgan-on-chip systems will help further predict drug absorption, metabolism, and clearance in the body. However, with current technologies, replicating the exact size and function of each organ to accurately reflect the physiological interactions among them is challenging [121]. In addition, the human body is an integrated whole, and hormones, hemodynamics, and even biorhythms affect the metabolism of drugs in vivo. If the organ-on-chip system could consistently and accurately predict the pharmacology of drug candidates, organ-on-chip models might replace animal test models in the future [122].

\section{Hepatocyte-like cell models for in vivo hepatotoxicity testing}

Drug metabolism differs in vitro and in vivo; therefore, preclinical evaluation of drug candidates in experimental 
animal models is an important step in drug development. However, owing to the differences between rodents and humans with respect to the metabolic and toxicological characteristics of drugs, accurately predicting the toxicity of drugs is often impossible [123]. To address this problem, chimeric mice with humanized livers were used for preclinical drug evaluation to replace traditional animal models [26]. Three types of chimeric mice with a humanized liver are frequently used for studies: urokinase-type plasminogen activator/severe combined immunodeficiency (uPA/SCID) mice, NOG mice expressing a thymidine kinase transgene (TK-NOG mice), and $\mathrm{Fah}^{-/-} / \mathrm{Rag}^{-/-} / \mathrm{Il}-2 \mathrm{rg}^{-/-}$(FRG) mice (humanized liver FRG mice) [124-126]. Immune deficiency and genetic modification in these mice allowed transplanted human liver cells to reproduce in the livers of these mice, resulting in chimeric mice with humanized livers that perform human drug metabolism and transformation functions [127].

Studies have found that the laboratory and histologic features of drug-induced liver toxicity in humanized mice mirrored those of humans [128-131]. For example, troglitazone is an antidiabetic drug that has been withdrawn from the market because of idiosyncratic severe liver injury. Its severe liver toxicity has never been induced in animal models until Kakuni et al. successfully detected it in chimeric mice with humanized liver [129]. Another study by $\mathrm{Xu}$ et al. [131] tested the doseresponse of the drug fialuridine, a nucleoside analog for hepatitis B virus (HBV) infections, in humanized TKNOG mice. Fialuridine did not display any toxicity in preclinical animal studies but was abruptly terminated in phase II clinical trials because seven of 15 clinical trial participants showed acute liver failure [132]. The authors found a dose-dependent liver toxicity in chimeric mice with a humanized liver as compared with nonhumanized mice. Although currently most chimeric mice with humanized liver models used in hepatotoxicity testing (including the works of Kakuni et al. and $\mathrm{Xu}$ et al. mentioned above) were generated by transplanting PHHs [133-135], the use of stem cells to serve as hepatocyte sources for chimeric mice with a humanized liver is promising because stem cells are easily obtained and can be large-scale produced [136] (Fig. 1).

Stem cell-derived HLCs have been used to develop humanized liver HBV infection models in mice and evaluate anti-HBV drugs. For instance, Yuan et al. [137] developed an animal model with a human chimeric liver to study in vivo HBV infection by engrafting hiPSCHLCs into $\mathrm{Fah}^{-/-} \mathrm{Rag}^{-/-} \mathrm{IL}-2 \mathrm{R}_{\mathrm{Cc}} \mathrm{C}^{-/} \mathrm{SCID}$ (FRGS) mice. As expected, the hHLC-FRGS mice reproduced HBV mimicking chronic HBV-caused viremia, and they were used to evaluate the effects of anti-HBV drugs. In the study, the combination of the well-demonstrated HBV entry inhibitor myrcludex $B$ with the clinical drug entecavir efficiently blocked HBV spread in hHLC-FRGS mice. Similarly, the authors also used HepaRG cells to construct an HBV-infected humanized mouse model to evaluate anti-HBV drugs, including myrcludex B, cyclosporin $A$, vanitaracin $A$, irbesartan, and ritonavir and demonstrated that myrcludex B and cyclosporin A were more effective than the other three drugs in suppressing HBV replication [138].

Nevertheless, chimeric mice with humanized liver have some disadvantages. Generating chimeric mice with a humanized liver is costly and time-consuming [139]. And the efficiency of in vivo engraftment and expansion of immature HLC is still low. In the Yuan et al. study, FRGS mice implanted with HepaRG cells showed only about $10 \%$ liver chimerism, which was lower than that for PHHs [138]. However, in vivo administration of 5D5, an agonist c-Met receptor antibody, greatly promoted the expansion of hiPSC-HLCs in Fah-deficient mice, and the liver chimerism exceeded $40 \%$ in transplanted mice [140]. Nagamoto et al. [141] demonstrated that transplanted HLCs with overexpression of FNK (a hyperactive mutant gene from Bcl-xL) into uPA/SCID mice could enhance the repopulation efficiency of human liver chimeric mice. In addition, $\mathrm{Ng}$ et al. developed an inverted colloid crystal scaffold whose 3D mechanical properties could be engineered to reproduce the extracellular niche sensed by hepatic progenitors during human development. The model could help integrate, vascularize, and function the organoids following implantation into livers of immune-deficient mice [142].

\section{Conclusions}

A large number of studies have shown that stem cellderived hepatocytes have great potential in regenerative medicine, disease modeling, and drug screening. Only when the function of HLCs is consistent with that of PHHs can they accurately predict drug toxicity; hence, the differentiation of stem cells into fully functional hepatocytes remains a major challenge. On the one hand, small molecule compounds can replace the role of cytokines to improve the efficiency of differentiation [143]. On the other, researchers pay more attention to changing the microenvironment of cell culture to improve differentiation efficiency [144]. In recent years, with the development of 3D culture techniques, liver tissue engineering has been transformed from the classic monolayer cell culture to more advanced organotypic liver models that allow for more precise control of the microenvironment [145].

There are still many limitations to the use of 3D culture that need to be considered. First, the 3D model has not been able to replace the 2D culture model on a large scale [146]. Second, the results vary among laboratories 
[147]; therefore, the repeatability rate needs to be improved and the detection endpoints of cell differentiation and drug screening need to be unified. Third, according to the current protocols, generating organoids are timeconsuming and costly [148]. To overcome these limitations, more technologies are needed, such as highthroughput microarray culture, 3D printing technology, and bionic scaffolds [149]. 3D culture combined with technology from materials science, bioengineering, and other fields will greatly improve the sensitivity and accuracy of drug screening.

In conclusion, the stem cell-based model provides an excellent platform for evaluating drug hepatotoxicity. In the future, combined with technologies such as geneediting, omics, and single-cell sequencing, stem cellderived HLC models will bring great benefits for drug toxicity and drug metabolism testing and also mechanisms of DILI and individualized medicine studies.

\section{Abbreviations}

DILI: Drug-induced liver injury; PHHs: Primary human hepatocytes; 3D: Threedimensional; 2D: Two-dimensional; HBV: Hepatitis B virus; HLCs: Hepatocytelike cells; hESCs: Human embryonic stem cells; hiPSCs: Human induced pluripotent stem cells; miRNAs: MicroRNAs; hMSCs: Human mesenchymal stem cells; hiHeps: Human-induced hepatocytes; DMSO: Dimethyl sulfoxide; CYP: Cytochrome P450; hECs: Human endothelial cells; ECM: Extracellular matrix; iDILI: Idiosyncratic drug-induced liver injury; FRG: Fah ${ }^{-1-}$ Rag $^{-1-} \mid \mathrm{L}-$ $2 \mathrm{R} \mathrm{C}^{-/-}$; uPA/SCID: Urokinase-type plasminogen activator/severe combined immunodeficiency

\section{Acknowledgements}

Not applicable.

\section{Authors' contributions}

MJ drafted the manuscript. QP and SZ contributed to the manuscript conception and the methodology. $Q P, X Y, W L, Q C, W Y, Y L$, and $S L$ reviewed and edited the manuscript. $Y G, Q P$, and $S Z$ provided financial support for the study. All authors read and approved the final manuscript.

\section{Funding}

This work was supported by the National Key R\&D Program of China (2018YFA0108200 and 2018YFC1106400), Guangdong Natural Science Foundation (2018A030313128), Science and Technology Program of Guangzhou (201803010086), and Natural Science Foundation of Xinjiang Uyghur Autonomous Region Project (2017D01C011 and 2016D01C017).

\section{Availability of data and materials}

All data are included in this published article.

Ethics approval and consent to participate Not applicable.

\section{Consent for publication}

Not applicable.

\section{Competing interests}

The authors declare that they have no competing interests.

\section{Author details}

${ }^{1}$ Department of Anesthesiology, Zhujiang Hospital, Southern Medical University, Guangzhou 510000, China. ²Department of Gynecology, Zhujiang Hospital, Southern Medical University, Guangzhou, China. ${ }^{3}$ General Surgery Center, Department of Hepatobiliary Surgery II, Guangdong Provincial Research Center for Artificial Organ and Tissue Engineering, Guangzhou Clinical Research and Transformation Center for Artificial Liver, Institute of
Regenerative Medicine, Zhujiang Hospital, Southern Medical University, Guangzhou, Guangdong Province, China.

Received: 12 August 2020 Accepted: 7 January 2021

Published online: 25 January 2021

\section{References}

1. Larrey D. Epidemiology and individual susceptibility to adverse drug reactions affecting the liver. Semin Liver Dis. 2002;22(2):145-55.

2. Verma S, Kaplowitz N. Diagnosis, management and prevention of druginduced liver injury. Gut. 2009;58(11):1555-64.

3. Bjornsson ES. Epidemiology, predisposing factors, and outcomes of druginduced liver injury. Clin Liver Dis. 2020;24(1):1-10.

4. Shen T, Liu Y, Shang J, Xie Q, Li J, Yan M, et al. Incidence and etiology of drug-induced liver injury in mainland China. Gastroenterology. 2019;156(8): 2230-41 e11.

5. Funk $C$, Roth $A$. Current limitations and future opportunities for prediction of DILI from in vitro. Arch Toxicol. 2017;91(1):131-42.

6. Chalasani NP, Hayashi PH, Bonkovsky HL, Navarro VJ, Lee WM, Fontana RJ, et al. ACG Clinical Guideline: the diagnosis and management of idiosyncratic drug-induced liver injury. Am J Gastroenterol. 2014;109(7):95066 quiz 67.

7. European Association for the Study of the Liver, Electronic address eee, Clinical Practice Guideline Panel C, Panel m, representative EGB. EASL Clinical Practice Guidelines: drug-induced liver injury. J Hepatol. 2019;70(6): 1222-61.

8. Yu YC, Mao YM, Chen CW, Chen JJ, Chen J, Cong WM, et al. CSH guidelines for the diagnosis and treatment of drug-induced liver injury. Hepatol Int. 2017;11(3):221-41.

9. Bell CC, Lauschke VM, Vorrink SU, Palmgren H, Duffin R, Andersson TB, et al. Transcriptional, functional, and mechanistic comparisons of stem cellderived hepatocytes, HepaRG cells, and three-dimensional human hepatocyte spheroids as predictive in vitro systems for drug-induced liver injury. Drug Metab Dispos. 2017:45(4):419-29.

10. Guguen-Guillouzo C, Guillouzo A. General review on in vitro hepatocyte models and their applications. Methods Mol Biol. 2010;640:1-40.

11. Gomez-Lechon MJ, Tolosa L, Conde I, Donato MT. Competency of different cell models to predict human hepatotoxic drugs. Expert Opin Drug Metab Toxicol. 2014;10(11):1553-68.

12. Thomson JA, Itskovitz-Eldor J, Shapiro SS, Waknitz MA, Swiergiel JJ, Marshall VS, et al. Embryonic stem cell lines derived from human blastocysts. Science. 1998;282(5391):1145-7.

13. Takayama K, Hagihara Y, Toba Y, Sekiguchi K, Sakurai F, Mizuguchi $H$. Enrichment of high-functioning human iPS cell-derived hepatocyte-like cells for pharmaceutical research. Biomaterials. 2018;161:24-32.

14. Gao X, Liu Y. A transcriptomic study suggesting human iPSC-derived hepatocytes potentially offer a better in vitro model of hepatotoxicity than most hepatoma cell lines. Cell Biol Toxicol. 2017;33(4):407-21.

15. Xu F, Liu J, Deng J, Chen X, Wang Y, Xu P, et al. Rapid and high-efficiency generation of mature functional hepatocyte-like cells from adipose-derived stem cells by a three-step protocol. Stem Cell Res Ther. 2015;6:193.

16. Ullah I, Subbarao RB, Rho GJ. Human mesenchymal stem cells - current trends and future prospective. Biosci Rep. 2015;35(2):e00191.

17. Huang $P$, Zhang L, Gao Y, He Z, Yao D, Wu Z, et al. Direct reprogramming of human fibroblasts to functional and expandable hepatocytes. Cell Stem Cell. 2014;14(3):370-84.

18. Fu GB, Huang WJ, Zeng M, Zhou X, Wu HP, Liu CC, et al. Expansion and differentiation of human hepatocyte-derived liver progenitor-like cells and their use for the study of hepatotropic pathogens. Cell Res. 2019;29(1):8-22.

19. Ranade AR, Wilson MS, McClanahan AM, Ball AJ. High content imaging and analysis enable quantitative in situ assessment of CYP3A4 using cryopreserved differentiated HepaRG cells. J Toxicol. 2014;2014:291054

20. Turpeinen M, Tolonen A, Chesne C, Guillouzo A, Uusitalo J, Pelkonen O. Functional expression, inhibition and induction of CYP enzymes in HepaRG cells. Toxicol in Vitro. 2009:23(4):748-53.

21. Gerets HH, Tilmant K, Gerin B, Chanteux H, Depelchin BO, Dhalluin S, et al. Characterization of primary human hepatocytes, HepG2 cells, and HepaRG cells at the mRNA level and CYP activity in response to inducers and their predictivity for the detection of human hepatotoxins. Cell Biol Toxicol. 2012; 28(2):69-87. 
22. Van Norman GA. Limitations of animal studies for predicting toxicity in clinical trials: is it time to rethink our current approach? JACC Basic Transl Sci. 2019;4(7):845-54.

23. Sahi J, Grepper S, Smith C. Hepatocytes as a tool in drug metabolism, transport and safety evaluations in drug discovery. Curr Drug Discov Technol. 2010;7(3):188-98.

24. Duval K, Grover H, Han LH, Mou Y, Pegoraro AF, Fredberg J, et al. Modeling physiological events in 2D vs. 3D cell culture. Physiology (Bethesda). 2017; 32(4):266-77.

25. Hannoun Z, Steichen C, Dianat N, Weber A, Dubart-Kupperschmitt A. The potential of induced pluripotent stem cell derived hepatocytes. J Hepatol. 2016;65(1):182-99.

26. Xu D, Peltz G. Can humanized mice predict drug "behavior" in humans? Annu Rev Pharmacol Toxicol. 2016;56:323-38.

27. Kia R, Sison RL, Heslop J, Kitteringham NR, Hanley N, Mills JS, et al. Stem cell-derived hepatocytes as a predictive model for drug-induced liver injury: are we there yet? Br J Clin Pharmacol. 2013;75(4):885-96.

28. Takahashi K, Yamanaka S. Induction of pluripotent stem cells from mouse embryonic and adult fibroblast cultures by defined factors. Cell. 2006;126(4): 663-76

29. Lee KD, Kuo TK, Whang-Peng J, Chung YF, Lin CT, Chou SH, et al. In vitro hepatic differentiation of human mesenchymal stem cells. Hepatology (Baltimore). 2004;40(6):1275-84.

30. Lee HJ, Jung J, Cho KJ, Lee CK, Hwang SG, Kim GJ. Comparison of in vitro hepatogenic differentiation potential between various placenta-derived stem cells and other adult stem cells as an alternative source of functional hepatocytes. Differentiation. 2012;84(3):223-31.

31. Campard D, Lysy PA, Najimi M, Sokal EM. Native umbilical cord matrix stem cells express hepatic markers and differentiate into hepatocyte-like cells. Gastroenterology. 2008;134(3):833-48.

32. Khanjani S, Khanmohammadi M, Zarnani AH, Talebi S, Edalatkhah $\mathrm{H}_{\text {, }}$ Eghtesad S, et al. Efficient generation of functional hepatocyte-like cells from menstrual blood-derived stem cells. J Tissue Eng Regen Med. 2015; 9(11):E124-34

33. Twaroski K, Mallanna SK, Jing R, DiFurio F, Urick A, Duncan SA. FGF2 mediates hepatic progenitor cell formation during human pluripotent stem cell differentiation by inducing the WNT antagonist NKD1. Genes Dev. 2015; 29(23):2463-74.

34. Ye JS, Su XS, Stoltz JF, de Isla N, Zhang L. Signalling pathways involved in the process of mesenchymal stem cells differentiating into hepatocytes. Cell Prolif. 2015;48(2):157-65.

35. Shan J, Schwartz RE, Ross NT, Logan DJ, Thomas D, Duncan SA, et al. Identification of small molecules for human hepatocyte expansion and iPS differentiation. Nat Chem Biol. 2013;9(8):514-20.

36. Hay DC, Fletcher J, Payne C, Terrace JD, Gallagher RC, Snoeys J, et al. Highly efficient differentiation of hESCs to functional hepatic endoderm requires ActivinA and Wnt3a signaling. Proc Natl Acad Sci U S A. 2008;105(34):12301-6.

37. Li S, Li M, Liu X, Yang Y, Wei Y, Chen Y, et al. Genetic and chemical screenings identify HDAC3 as a key regulator in hepatic differentiation of human pluripotent stem cells. Stem Cell Rep. 2018;11(1):22-31.

38. Baxter M, Withey S, Harrison S, Segeritz CP, Zhang F, Atkinson-Dell R, et al. Phenotypic and functional analyses show stem cell-derived hepatocyte-like cells better mimic fetal rather than adult hepatocytes. J Hepatol. 2015;62(3): 581-9.

39. Kvist AJ, Kanebratt KP, Walentinsson A, Palmgren H, O'Hara M, Bjorkbom A et al. Critical differences in drug metabolic properties of human hepatic cellular models, including primary human hepatocytes, stem cell derived hepatocytes, and hepatoma cell lines. Biochem Pharmacol. 2018;155:124-40.

40. Kratochwil NA, Meille C, Fowler S, Klammers F, Ekiciler A, Molitor B, et al. Metabolic profiling of human long-term liver models and hepatic clearance predictions from in vitro data using nonlinear mixed-effects modeling. AAPS J. 2017;19(2):534-50.

41. Godoy P, Schmidt-Heck W, Natarajan K, Lucendo-Villarin B, Szkolnicka D, Asplund $A$, et al. Gene networks and transcription factor motifs defining the differentiation of stem cells into hepatocyte-like cells. J Hepatol. 2015;63(4):934-42.

42. Asumda FZ, Hatzistergos KE, Dykxhoorn DM, Jakubski S, Edwards J, Thomas E, et al. Differentiation of hepatocyte-like cells from human pluripotent stem cells using small molecules. Differentiation. 2018;101:16-24.

43. Siller R, Greenhough S, Naumovska E, Sullivan GJ. Small-molecule-driven hepatocyte differentiation of human pluripotent stem cells. Stem Cell Rep. 2015:4(5):939-52.
44. Boon R, Kumar M, Tricot T, Elia I, Ordovas L, Jacobs F, et al. Amino acid levels determine metabolism and CYP450 function of hepatocytes and hepatoma cell lines. Nat Commun. 2020;11(1):1393.

45. Jellali R, Lereau Bernier M, Tauran Y, Gilard F, Danoy M, Kido T, et al. Metabolomic profiling during the differentiation of human induced pluripotent stem cells into hepatocyte-like cells. Differentiation. 2020;112: $17-26$.

46. Takayama K, Inamura M, Kawabata K, Katayama K, Higuchi M, Tashiro K, et al. Efficient generation of functional hepatocytes from human embryonic stem cells and induced pluripotent stem cells by HNF4alpha transduction. Mol Ther. 2012;20(1):127-37.

47. Takayama K, Inamura M, Kawabata K, Sugawara M, Kikuchi K, Higuchi M, et al. Generation of metabolically functioning hepatocytes from human pluripotent stem cells by FOXA2 and HNF1alpha transduction. J Hepatol. 2012:57(3):628-36

48. Chien Y, Chang YL, Li HY, Larsson M, Wu WW, Chien CS, et al. Synergistic effects of carboxymethyl-hexanoyl chitosan, cationic polyurethane-short branch PEI in miR122 gene delivery: accelerated differentiation of iPSCs into mature hepatocyte-like cells and improved stem cell therapy in a hepatic failure model. Acta Biomater. 2015;13:228-44.

49. Jung KH, McCarthy RL, Zhou C, Uprety N, Barton MC, Beretta L. MicroRNA regulates hepatocytic differentiation of progenitor cells by targeting YAP1. Stem Cells. 2016;34(5):1284-96.

50. Vinken M, Hengstler JG. Characterization of hepatocyte-based in vitro systems for reliable toxicity testing. Arch Toxicol. 2018;92(10):2981-6.

51. Huang $P, H e ~ Z$, Ji S, Sun H, Xiang D, Liu C, et al. Induction of functional hepatocyte-like cells from mouse fibroblasts by defined factors. Nature. 2011:475(7356):386-9

52. Rogue A, Lambert C, Spire C, Claude N, Guillouzo A. Interindividual variability in gene expression profiles in human hepatocytes and comparison with HepaRG cells. Drug Metab Dispos. 2012;40(1):151-8.

53. Tolosa L, Gomez-Lechon MJ, Jimenez N, Hervas D, Jover R, Donato MT. Advantageous use of HepaRG cells for the screening and mechanistic study of drug-induced steatosis. Toxicol Appl Pharmacol. 2016;302:1-9.

54. Wu Y, Geng XC, Wang JF, Miao YF, Lu YL, Li B. The HepaRG cell line, a superior in vitro model to L-02, HepG2 and hiHeps cell lines for assessing drug-induced liver injury. Cell Biol Toxicol. 2016;32(1):37-59.

55. Rodrigues RM, Bouhifd M, Bories G, Sacco MG, Gribaldo L, Fabbri M, et al. Assessment of an automated in vitro basal cytotoxicity test system based on metabolically-competent cells. Toxicol in Vitro. 2013;27(2):760-7.

56. Morgan K, Bryans A, Brzeszczynski F, Samuel K, Treskes P, Brzeszczynska J, et al. Oxygen plasma substrate and specific nanopattern promote early differentiation of HepaRG progenitors. Tissue Eng A. 2020;26(19-20):1064-76.

57. Wang ZY, Li WJ, Li QG, Jing HS, Yuan TJ, Fu GB, et al. A DMSO-free hepatocyte maturation medium accelerates hepatic differentiation of HepaRG cells in vitro. Biomed Pharmacother. 2019;116:109010.

58. Sun M, Wong JY, Nugraha B, Ananthanarayanan A, Liu Z, Lee F, et al. Cleavable cellulosic sponge for functional hepatic cell culture and retrieval. Biomaterials. 2019:201:16-32.

59. Lu J, Einhorn S, Venkatarangan L, Miller M, Mann DA, Watkins PB, et al. Morphological and functional characterization and assessment of iPSCderived hepatocytes for in vitro toxicity testing. Toxicol Sci. 2015;147(1):3954.

60. Kang SJ, Lee HM, Park Yl, Yi H, Lee H, So B, et al. Chemically induced hepatotoxicity in human stem cell-induced hepatocytes compared with primary hepatocytes and HepG2. Cell Biol Toxicol. 2016;32(5):403-17.

61. Avior $Y$, Levy G, Zimerman M, Kitsberg D, Schwartz R, Sadeh R, et al. Microbial-derived lithocholic acid and vitamin K2 drive the metabolic maturation of pluripotent stem cells-derived and fetal hepatocytes. Hepatology (Baltimore). 2015;62(1):265-78.

62. Kim DE, Jang MJ, Kim YR, Lee JY, Cho EB, Kim E, et al. Prediction of druginduced immune-mediated hepatotoxicity using hepatocyte-like cells derived from human embryonic stem cells. Toxicology. 2017;387:1-9.

63. Ware BR, Berger DR, Khetani SR. Prediction of drug-induced liver injury in micropatterned co-cultures containing iPSC-derived human hepatocytes. Toxicol Sci. 2015;145(2):252-62.

64. Holmgren G, Sjogren AK, Barragan I, Sabirsh A, Sartipy P, Synnergren J, et al. Long-term chronic toxicity testing using human pluripotent stem cellderived hepatocytes. Drug Metab Dispos. 2014;42(9):1401-6.

65. Kietzmann T. Metabolic zonation of the liver: the oxygen gradient revisited. Redox Biol. 2017;11:622-30. 
66. Rashidi H, Alhaque S, Szkolnicka D, Flint O, Hay DC. Fluid shear stress modulation of hepatocyte-like cell function. Arch Toxicol. 2016;90(7): 1757-61.

67. Cipriano M, Freyer N, Knospel F, Oliveira NG, Barcia R, Cruz PE, et al. Self-assembled 3D spheroids and hollow-fibre bioreactors improve MSCderived hepatocyte-like cell maturation in vitro. Arch Toxicol. 2017;91(4): 1815-32.

68. Vorrink SU, Ullah S, Schmidt S, Nandania J, Velagapudi V, Beck O, et al. Endogenous and xenobiotic metabolic stability of primary human hepatocytes in long-term 3D spheroid cultures revealed by a combination of targeted and untargeted metabolomics. FASEB J. 2017;31(6):2696-708,

69. Tasnim F, Toh YC, Qu Y, Li H, Phan D, Narmada BC, et al. Functionally enhanced human stem cell derived hepatocytes in galactosylated cellulosic sponges for hepatotoxicity testing. Mol Pharm. 2016;13(6):1947-57.

70. Lancaster MA, Knoblich JA. Organogenesis in a dish: modeling development and disease using organoid technologies. Science. 2014; 345(6194):1247125

71. Simian M, Bissell MJ. Organoids: a historical perspective of thinking in three dimensions. J Cell Biol. 2017;216(1):31-40.

72. Clevers H. Modeling development and disease with organoids. Cell. 2016; 165(7):1586-97.

73. Fatehullah A, Tan SH, Barker N. Organoids as an in vitro model of human development and disease. Nat Cell Biol. 2016;18(3):246-54.

74. Huch M, Koo BK. Modeling mouse and human development using organoid cultures. Development. 2015;142(18):3113-25.

75. Goulart E, de Caires-Junior LC, Telles-Silva KA, Araujo BHS, Kobayashi GS, Musso CM, et al. Adult and iPS-derived non-parenchymal cells regulate liver organoid development through differential modulation of Wnt and TGFbeta. Stem Cell Res Ther. 2019;10(1):258

76. Koui Y, Kido T, Ito T, Oyama H, Chen SW, Katou Y, et al. An in vitro human liver model by iPSC-derived parenchymal and non-parenchymal cells. Stem Cell Rep. 2017:9(2):490-8.

77. Ardalani H, Sengupta S, Harms V, Vickerman V, Thomson JA, Murphy WL. 3$D$ culture and endothelial cells improve maturity of human pluripotent stem cell-derived hepatocytes. Acta Biomater. 2019;95:371-81.

78. Takebe T, Sekine K, Enomura M, Koike H, Kimura M, Ogaeri T, et al, Vascularized and functional human liver from an iPSC-derived organ bud transplant. Nature. 2013;499(7459):481-4.

79. Pettinato G, Lehoux S, Ramanathan R, Salem MM, He LX, Muse O, et al. Generation of fully functional hepatocyte-like organoids from human induced pluripotent stem cells mixed with endothelial cells. Sci Rep. 2019; 9(1):8920.

80. Furuya K, Zheng YW, Sako D, Iwasaki K, Zheng DX, Ge JY, et al. Enhanced hepatic differentiation in the subpopulation of human amniotic stem cells under 3D multicellular microenvironment. World J Stem Cells. 2019;11(9): 705-21

81. Schneeberger K, Sanchez-Romero N, Ye S, van Steenbeek FG, Oosterhoff LA, Pla Palacin I, et al. Large-scale production of LGR5-positive bipotential human liver stem cells. Hepatology (Baltimore). 2020;72(1):257-70.

82. Wu F, Wu D, Ren Y, Huang Y, Feng B, Zhao N, et al. Generation of hepatobiliary organoids from human induced pluripotent stem cells. $J$ Hepatol. 2019;70(6):1145-58.

83. Mun SJ, Ryu JS, Lee MO, Son YS, Oh SJ, Cho HS, et al. Generation of expandable human pluripotent stem cell-derived hepatocyte-like liver organoids. J Hepatol. 2019;71(5):970-85.

84. Rashidi H, Luu NT, Alwahsh SM, Ginai M, Alhaque S, Dong H, et al. 3D human liver tissue from pluripotent stem cells displays stable phenotype in vitro and supports compromised liver function in vivo. Arch Toxicol. 2018:92(10):3117-29.

85. Sgodda M, Dai Z, Zweigerdt R, Sharma AD, Ott M, Cantz T. A scalable approach for the generation of human pluripotent stem cell-derived hepatic organoids with sensitive hepatotoxicity features. Stem Cells Dev. 2017;26(20):1490-504.

86. Croce S, Peloso A, Zoro T, Avanzini MA, Cobianchi L. A hepatic scaffold from decellularized liver tissue: food for thought. Biomolecules. 2019;9(12):813.

87. Jain E, Damania A, Kumar A. Biomaterials for liver tissue engineering Hepatol Int. 2014;8(2):185-97.

88. Aisenbrey EA, Murphy WL. Synthetic alternatives to Matrigel. Nat Rev Mater. 2020;5(7):539-51.

89. Liu H, Wang Y, Cui K, Guo Y, Zhang X, Qin J. Advances in hydrogels in organoids and organs-on-a-chip. Adv Mater. 2019;31(50):e1902042.
90. Saheli M, Sepantafar M, Pournasr B, Farzaneh Z, Vosough M, Piryaei A, et al. Three-dimensional liver-derived extracellular matrix hydrogel promotes liver organoids function. J Cell Biochem. 2018;119(6):4320-33.

91. Kruger M, Oosterhoff LA, van Wolferen ME, Schiele SA, Walther A, Geijsen N, et al. Cellulose nanofibril hydrogel promotes hepatic differentiation of human liver organoids. Adv Healthc Mater. 2020;9(6):e1901658.

92. Vishwakarma SK, Bardia A, Lakkireddy C, Nagarapu R, Habeeb MA, Khan AA. Bioengineered humanized livers as better three-dimensional drug testing model system. World J Hepatol. 2018;10(1):22-33.

93. Abazari MF, Soleimanifar F, Enderami SE, Nasiri N, Nejati F, Mousavi SA, et al. Decellularized amniotic membrane scaffolds improve differentiation of iPSC to functional hepatocyte-like cells. J Cell Biochem. 2020;121(2):1169-81.

94. Mobarra N, Soleimani M, Ghayour-Mobarhan M, Safarpour S, Ferns GA Pakzad R, et al. Hybrid poly-l-lactic acid/poly (epsilon-caprolactone) nanofibrous scaffold can improve biochemical and molecular markers of human induced pluripotent stem cell-derived hepatocyte-like cells. J Cell Physiol. 2019;234(7):11247-55.

95. Goulart E, de Caires-Junior LC, Telles-Silva KA, Araujo BHS, Rocco SA, Sforca $M$, et al. 3D bioprinting of liver spheroids derived from human induced pluripotent stem cells sustain liver function and viability in vitro. Biofabrication. 2019;12(1):015010.

96. Ma X, Qu X, Zhu W, Li YS, Yuan S, Zhang H, et al. Deterministically patterned biomimetic human iPSC-derived hepatic model via rapid 3D bioprinting. Proc Natl Acad Sci U S A. 2016;113(8):2206-11.

97. Liao W, Wang J, Xu J, You F, Pan M, Xu X, et al. High-throughput threedimensional spheroid tumor model using a novel stamp-like tool. J Tissue Eng. 2019;10:2041731419889184.

98. Zhang B, Li Y, Wang G, Jia Z, Li H, Peng Q, et al. Fabrication of agarose concave petridish for 3D-culture microarray method for spheroids formation of hepatic cells. J Mater Sci Mater Med. 2018;29(5):49.

99. Takebe T, Sekine K, Kimura M, Yoshizawa E, Ayano S, Koido M, et al. Massive and reproducible production of liver buds entirely from human pluripotent stem cells. Cell Rep. 2017;21(10):2661-70.

100. Takayama K, Morisaki Y, Kuno S, Nagamoto Y, Harada K, Furukawa N, et al. Prediction of interindividual differences in hepatic functions and drug sensitivity by using human iPS-derived hepatocytes. Proc Natl Acad Sci U S A. 2014;111(47):16772-7

101. Huch M, Gehart H, van Boxtel R, Hamer K, Blokzijl F, Verstegen MM, et al. Long-term culture of genome-stable bipotent stem cells from adult human liver. Cell. 2015;160(1-2):299-312.

102. Ouchi R, Togo S, Kimura M, Shinozawa T, Koido M, Koike H, et al. Modeling steatohepatitis in humans with pluripotent stem cell-derived organoids. Cell Metab. 2019;30(2):374-84 e6.

103. Kim J, Kim Y, Choi J, Jung H, Lee K, Kang J, et al. Recapitulation of methotrexate hepatotoxicity with induced pluripotent stem cell-derived hepatocytes from patients with rheumatoid arthritis. Stem Cell Res Ther 2018;9(1):357.

104. Akbari S, Sevinc GG, Ersoy N, Basak O, Kaplan K, Sevinc K, et al. Robust, longterm culture of endoderm-derived hepatic organoids for disease modeling. Stem Cell Rep. 2019;13(4):627-41.

105. Wang S, Wang X, Tan Z, Su Y, Liu J, Chang M, et al. Human ESC-derived expandable hepatic organoids enable therapeutic liver repopulation and pathophysiological modeling of alcoholic liver injury. Cell Res. 2019;29(12): 1009-26.

106. Luni C, Giulitti S, Serena E, Ferrari L, Zambon A, Gagliano O, et al. Highefficiency cellular reprogramming with microfluidics. Nat Methods. 2016; 13(5):446-52

107. Yen MH, Wu YY, Liu YS, Rimando M, Ho JH, Lee OK. Efficient generation of hepatic cells from mesenchymal stromal cells by an innovative biomicrofluidic cell culture device. Stem Cell Res Ther. 2016;7(1):120.

108. Wang $Y$, Wang H, Deng $P$, Chen W, Guo Y, Tao T, et al. In situ differentiation and generation of functional liver organoids from human iPSCs in a 3D perfusable chip system. Lab Chip. 2018;18(23):3606-16

109. Au SH, Chamberlain MD, Mahesh S, Sefton MV, Wheeler AR. Hepatic organoids for microfluidic drug screening. Lab Chip. 2014;14(17):3290-9.

110. Skardal A, Murphy SV, Devarasetty M, Mead I, Kang HW, Seol YJ, et al. Multitissue interactions in an integrated three-tissue organ-on-a-chip platform. Sci Rep. 2017;7(1):8837.

111. Stucki AO, Stucki JD, Hall SR, Felder M, Mermoud Y, Schmid RA, et al. A lung-on-a-chip array with an integrated bio-inspired respiration mechanism. Lab Chip. 2015;15(5):1302-10. 
112. Rayner SG, Phong KT, Xue J, Lih D, Shankland SJ, Kelly EJ, et al. Reconstructing the human renal vascular-tubular unit in vitro. Adv Healthc Mater. 2018;7(23):e1801120

113. Kim HJ, Li H, Collins JJ, Ingber DE. Contributions of microbiome and mechanical deformation to intestinal bacterial overgrowth and inflammation in a human gut-on-a-chip. Proc Natl Acad Sci U S A. 2016; 113(1):E7-15.

114. Mao M, Bei HP, Lam CH, Chen P, Wang S, Chen Y, et al. Human-on-leaf-chip: a biomimetic vascular system integrated with chamber-specific organs. Small. 2020;16(22):e2000546.

115. Choucha-Snouber L, Aninat C, Grsicom L, Madalinski G, Brochot C, Poleni PE, et al. Investigation of ifosfamide nephrotoxicity induced in a liver-kidney coculture biochip. Biotechnol Bioeng. 2013;110(2):597-608.

116. Lin N, Zhou X, Geng X, Drewell C, Hubner J, Li Z, et al. Repeated dose multi-drug testing using a microfluidic chip-based coculture of human liver and kidney proximal tubules equivalents. Sci Rep. 2020;10(1):8879.

117. Maschmeyer I, Lorenz AK, Schimek K, Hasenberg T, Ramme AP, Hubner J, et al. A four-organ-chip for interconnected long-term co-culture of human intestine, liver, skin and kidney equivalents. Lab Chip. 2015;15(12):2688-99.

118. Schimek K, Frentzel S, Luettich K, Bovard D, Rutschle I, Boden L, et al. Human multi-organ chip co-culture of bronchial lung culture and liver spheroids for substance exposure studies. Sci Rep. 2020;10(1):7865.

119. Satoh T, Sugiura S, Shin K, Onuki-Nagasaki R, Ishida S, Kikuchi K, et al. A multi-throughput multi-organ-on-a-chip system on a plate formatted pneumatic pressure-driven medium circulation platform. Lab Chip. 2017; 18(1):115-25.

120. Skardal A, Aleman J, Forsythe S, Rajan S, Murphy S, Devarasetty M, et al. Drug compound screening in single and integrated multi-organoid bodyon-a-chip systems. Biofabrication. 2020;12(2):025017.

121. Moradi E, Jalili-Firoozinezhad S, Solati-Hashjin M. Microfluidic organ-on-achip models of human liver tissue. Acta Biomater. 2020;116:67-83.

122. Liu X, Zheng W, Jiang X. Cell-based assays on microfluidics for drug screening. ACS Sens. 2019;4(6):1465-75.

123. Barzi M, Pankowicz FP, Zorman B, Liu X, Legras X, Yang D, et al. A novel humanized mouse lacking murine P450 oxidoreductase for studying human drug metabolism. Nat Commun. 2017:8(1):39.

124. Naritomi Y, Sanoh S, Ohta S. Chimeric mice with humanized liver: application in drug metabolism and pharmacokinetics studies for drug discovery. Drug Metab Pharmacokinet. 2018;33(1):31-9.

125. Grompe M, Strom S. Mice with human livers. Gastroenterology. 2013;145(6): 1209-14.

126. Nishimura T, Hu Y, Wu M, Pham E, Suemizu H, Elazar M, et al. Using chimeric mice with humanized livers to predict human drug metabolism and a drug-drug interaction. J Pharmacol Exp Ther. 2013;344(2):388-96.

127. Peltz G. Can 'humanized' mice improve drug development in the $21 \mathrm{st}$ century? Trends Pharmacol Sci. 2013;34(5):255-60.

128. Xu D, Wu M, Nishimura S, Nishimura T, Michie SA, Zheng M, et al. Chimeric TK-NOG mice: a predictive model for cholestatic human liver toxicity. J Pharmacol Exp Ther. 2015;352(2):274-80

129. Kakuni M, Morita M, Matsuo K, Katoh Y, Nakajima M, Tateno C, et al. Chimeric mice with a humanized liver as an animal model of troglitazoneinduced liver injury. Toxicol Lett. 2012;214(1):9-18.

130. Yamamoto T, Tomizawa K, Fujikawa M, Sato Y, Yamada H, Horii I. Evaluation of human hepatocyte chimeric mice as a model for toxicological investigation using panomic approaches--effect of acetaminophen on the expression profiles of proteins and endogenous metabolites in liver, plasma and urine. J Toxicol Sci. 2007;32(3):205-15.

131. Xu D, Nishimura T, Nishimura S, Zhang H, Zheng M, Guo YY, et al. Fialuridine induces acute liver failure in chimeric TK-NOG mice: a model for detecting hepatic drug toxicity prior to human testing. Plos Med. 2014; 11(4):e1001628.

132. McKenzie R, Fried MW, Sallie R, Conjeevaram H, Di Bisceglie AM, Park Y, et al. Hepatic failure and lactic acidosis due to fialuridine (FIAU), an investigational nucleoside analogue for chronic hepatitis B. N Engl J Med. 1995;333(17):1099-105.

133. Uchida M, Tajima Y, Kakuni M, Kageyama Y, Okada T, Sakurada E, et al. Organic anion-transporting polypeptide (OATP)-mediated drug-drug interaction study between rosuvastatin and cyclosporine A in chimeric mice with humanized liver. Drug Metab Dispos. 2018;46(1):11-9.

134. Torres S, Baulies A, Insausti-Urkia N, Alarcon-Vila C, Fucho R, Solsona-Vilarrasa $E$, et al. Endoplasmic reticulum stress-induced upregulation of STARD1 promotes acetaminophen-induced acute liver failure. Gastroenterology. 2019;157(2):552-68.

135. Ekdahl A, Weidolf L, Baginski M, Morikawa Y, Thompson RA, Wilson ID. The metabolic fate of fenclozic acid in chimeric mice with a humanized liver. Arch Toxicol. 2018;92(9):2819-28.

136. Yoshizato K, Tateno C. A mouse with humanized liver as an animal model for predicting drug effects and for studying hepatic viral infection: where to next? Expert Opin Drug Metab Toxicol. 2013;9(11):1419-35.

137. Yuan L, Liu X, Zhang L, Li X, Zhang Y, Wu K, et al. A chimeric humanized mouse model by engrafting the human induced pluripotent stem cellderived hepatocyte-like cell for the chronic hepatitis B virus infection. Front Microbiol. 2018;9:908.

138. Yuan L, Liu X, Zhang L, Zhang Y, Chen Y, Li X, et al. Optimized HepaRG is a suitable cell source to generate the human liver chimeric mouse model for the chronic hepatitis B virus infection. Emerg Microbes Infect. 2018;7(1):144.

139. Scheer N, Wilson ID. A comparison between genetically humanized and chimeric liver humanized mouse models for studies in drug metabolism and toxicity. Drug Discov Today. 2016;21(2):250-63.

140. Yuan L, Zhang Y, Liu X, Chen Y, Zhang L, Cao J, et al. Agonist C-met monoclonal antibody augments the proliferation of hiPSC-derived hepatocyte-like cells and improves cell transplantation therapy for liver failure in mice. Theranostics. 2019:9(7):2115-28.

141. Nagamoto Y, Takayama K, Tashiro K, Tateno C, Sakurai F, Tachibana M, et al. Efficient engraftment of human induced pluripotent stem cell-derived hepatocyte-like cells in UPA/SCID mice by overexpression of FNK, a BCl-xL mutant gene. Cell Transplant. 2015;24(6):1127-38.

142. Ng SS, Saeb-Parsy K, Blackford SJl, Segal JM, Serra MP, Horcas-Lopez M, et al. Human iPS derived progenitors bioengineered into liver organoids using an inverted colloidal crystal poly (ethylene glycol) scaffold. Biomaterials. 2018; 182:299-311.

143. Du C, Feng Y, Qiu D, Xu Y, Pang M, Cai N, et al. Highly efficient and expedited hepatic differentiation from human pluripotent stem cells by pure small-molecule cocktails. Stem Cell Res Ther. 2018;9(1):58.

144. Willemse J, Lieshout R, van der Laan LJW, Verstegen MMA. From organoids to organs: bioengineering liver grafts from hepatic stem cells and matrix. Best Pract Res Clin Gastroenterol. 2017;31(2):151-9.

145. Zeng F, Zhang Y, Han X, Weng J, Gao Y. Liver buds and liver organoids: new tools for liver development, disease and medical application. Stem Cell Rev Rep. 2019;15(6):774-84.

146. Antoni D, Burckel H, Josset E, Noel G. Three-dimensional cell culture: a breakthrough in vivo. Int J Mol Sci. 2015;16(3):5517-27.

147. Underhill GH, Khetani SR. Bioengineered liver models for drug testing and cell differentiation studies. Cell Mol Gastroenterol Hepatol. 2018;5(3):426-39 e1.

148. Nantasanti S, de Bruin A, Rothuizen J, Penning LC, Schotanus BA. Concise review: organoids are a powerful tool for the study of liver disease and personalized treatment design in humans and animals. Stem Cells Transl Med. 2016:5(3):325-30.

149. da Silva MA, Vieira S, Zhao X, Mao Z, Gao C, Oliveira JM, et al. Advanced biomaterials and processing methods for liver regeneration: state-of-the-art and future trends. Adv Healthc Mater. 2020;9(5):e1901435.

\section{Publisher's Note}

Springer Nature remains neutral with regard to jurisdictional claims in published maps and institutional affiliations. 